\title{
Studying Copper Electropolishing Inhibition in Presence of Some Organic Alcohols
}

\author{
Azza A. Attia, ${ }^{a}$ Essam M.EImelegy, ${ }^{a}$ MervetteEl Batouti ${ }^{b, *}$ \\ and Abdel-Moneim M. Ahmed ${ }^{b}$ \\ ${ }^{a}$ Chemistry Department, Faculty of Science, Zagazig University, Egypt \\ ${ }^{b}$ Chemistry Department, Faculty of Science, Alexandria University, Egypt
}

Received 09 March 2015; accepted 02 March 2016

\begin{abstract}
Electro polishing is defined as anodic corrosion. The issue of the effects of corrosion on structural integrity of metal surfaces has been a question of concern for some time. The uses of chemical corrosion inhibitors are common in production and processing operations. Nevertheless, the challenge is to develop a new class of corrosion inhibitors to protect the materials, due to the economic importance of copper there are several researches deals with acceleration and inhibition of this process. In this paper the electropolishing process inhibited with different ratio by addition of some organic alcohols (methanol, ethanol,propanol, and isopropanol) by addition with concentration $(2,5,10,15,20,25$ and $30 \%)$.The results reveal that these organic alcohols have a strongest inhibitive effect ranging from $8.7-53.8 \%$ and the thermodynamic parameters were present.
\end{abstract}

Keywords: Electropolishing of copper, organic alcohols, limiting current, inhibition of corrosion, thermodynamic parameters.

\section{Introduction}

Corrosion is an electrochemical process that involves the rearrangement of electrons between metal surface and an aqueous electrolyte solution. Corrosion of materials is a bigproblemthat receive interest of scientists whose concern in the technological world., scientists are persistent in seeking better and more efficient ways of combating the corrosion of metals. Addition of corrosion inhibitors to the corrosion environment with respect to the other methods of corrosion inhibition has been employed [1-2]. The use of inhibitors is one of the most practical methods for protection against corrosion in acidic media. To be

\footnotetext{
* Corresponding author. E-mail address: mervette_b@yahoo.com
} 
effective, an inhibitor must also transfer water from the metal surface, interact with anodic or cathodic reaction sites to retard the oxidation and reduction corrosion reaction, and prevent transportation of water and corrosion-active species on the metal surface. Copper is a material commonly used in heating and cooling systems. Scale and corrosion products have a negative effect on heat transfer, and they cause a decrease in the heating efficiency of the equipments which is a big problem in industrial processes.

Many corrosion inhibitors can be used to eliminate the undesirable destructive effect and prevent metal dissolution. Copper normally does not displace hydrogen from acid solutions and, therefore, is virtually unattached in nonoxidizing conditions. In fact, the uprising hydrogen bubbles induce a radial momentum transfer, which enhances the rate of copper corrosion [3]

Corrosion inhibitors can be used to prevent copper dissolution. Amines are known to be very effective inhibitors for metal and alloys in different corrosion media. Benzotriazole, for instances, was studied and found to have excellent inhibition properties in several corrosive environments [4]. The molecule contains nitrogen atoms and it is also useful in preventing copper staining and tarnishing [5]. The electropolishing process reported to be inhibited with different ratio by the addition of some organic aldehydes [6] and Organic compounds containing polar groups, including nitrogen, sulfur, oxygen, and heterocyclic compounds with polar functional groups and conjugated double bonds have been reported to inhibit copper corrosion [7-13]. The inhibiting action of these organic compounds is usually attributed to their interactions with the copper surface via their adsorption. Polar functional groups are regarded as the reaction center that stabilizes the adsorption process, in general, the adsorption of an inhibitor on a metal surface depends on the nature and the surface charge of the metal, the adsorption mode, its chemical structure and the type of electrolyte solution [14].

The phenomenon of electropolishing is first discovered by Jaquet [15]. A lot of work has been done on this phenomenon owing to its importance as a metal finishing process. A great deal of work has been directed to study the mechanism of electro polishing as well as to establish conditions for different metals and alloys involved in the process.

Mechanistic studies have revealed that electro polishing is diffusion controlled process taking place at the limiting current which is attained most probably when the diffusion layer becomes saturated with $\mathrm{Cu}$ in, electropolishing of copper.

Therefore, the values of the limiting current which determined the polishing rate depends on the rate of mass transfer of $\mathrm{Cu}^{+2}$ from the diffusion layer to the bulk solution. The latter depends on the relative movement of the ions at the anode and in the electrolyte. Earlier works studied the factors affecting the limiting current have overlooked the effect of anode geometry as an important factor in determining the value of the limiting current.

Other work based on electron diffraction showed.That, the film is an oxide. Hull cell studies by Lurking suggested that, copper oxides are formed during electro polishing of copper in $\mathrm{H}_{3} \mathrm{PO}_{4}[16]$. 
It can be denied that, a viscous layer is present at the surface of copper anodes during electro polishing as shown by the work of Walton [17].

The objective of this study is to investigate the effect of some organic alcohols (methanol, ethanol, propanol, and isopropanol) on the inhibition of copper corrosion in phosphoric acid at different conditions. The rate of copper corrosion is determined by measuring the anodic limiting current.

\section{Experimental Procedure \\ Chemicals}

Analytical grade $\mathrm{H}_{3} \mathrm{PO}_{4}(98 \% \mathrm{w} / \mathrm{w})$ and double distilled water used to prepare the electrolyte. The organic alcohols were used in this work are methanol, ethanol, propanol, and isopropanol.
Methanol
Ethanol
Propanol
Isopropanol
$\mathrm{CH}_{3}---\mathrm{OH}$
$\mathrm{CH}_{3--} \mathrm{CH}_{2--\mathrm{OH}}$
$\mathrm{CH}_{3}--\mathrm{CH}_{2}--\mathrm{CH}_{2}--\mathrm{OH}$
$\left(\mathrm{CH}_{3}\right)_{2}-\mathrm{CH}-\mathrm{OH}$

\section{Apparatus and Procedure}

The cell and electrical circuit used in the present work showed in previous work [6]. The cell consists of a rectangular plastic container having the dimensions $5.1 \times 5 \times 10 \mathrm{~cm}$ with electrodes fill-in the whole cross section. The electrodes were rectangular copper sheets of $10 \mathrm{~cm}$ height and $5 \mathrm{~cm}$ width. Electrode separation was $5 \mathrm{~cm}$. A porous PVC diaphragm was used to prevent the effect due to $\mathrm{H}_{2}$ bubbles. The electrical circuit consists of 6V D.C. power supply, while a voltmeter is connected in parallel to the cell to measure the voltage and multirange ammeter connected in series with cell to measure the current.

\section{Measurements of the Limiting Current}

Polarization curves were obtained by increasing the cell current step wise and the steady state anode potential against a reference electrode consisted of a wire immersed in a cup ofLuggin tubefilled with phosphoric acid concentration similar to that in the cell, the tip of the Luggin tube was placed 0.5-from the anode. The potential difference between the anode and the reference was measured by high impedance potentiometer. Five phosphoric acid concentrations $(6,8,10,12$ and $14 \mathrm{M})$ were prepared from Analar grade phosphoric acid distilled water. The anode height varied from $1-5 \mathrm{~cm}$. Before each run, the back part of the anode was insulated with polystyrene lacquers and the active surface of the anode was polished with fine emery paper, decreased with trichloroethylene, washed with alcohol and finally rinsed in distilled water. Electrode treatment was similar to that used by Wilke [18]. Organic acid concentration were $10^{-5}-10^{-2} \mathrm{~mol} .1^{-1}$. The rate of electropolishing of copper was determined at $25^{\circ} \mathrm{C}$. 


\section{Results and Discussion \\ Effect of alcohol concentration on the limiting current density}

The observed limiting current density, which represents the rate of copper metal corrosion in phosphoric acid at $25^{\circ} \mathrm{C}$, decrease with increasing the concentration of the organic alcohols under study.

It found that the limiting current decreases with increasing the concentration of alcohols. From the practical point of view and on the basis of results obtained the uses of alcohols studied in the concentration range between $(2,5,10,15,20,25$ and $30 \%$ ) inhibit the corrosion of copper metal in $8 \mathrm{M} \mathrm{H}_{3} \mathrm{PO}_{4}$ acid $[19,20]$. The limiting current in the absence of organic alcohols (I), and in the presence of organic alcohols (IL), the percentage inhibition can be calculated from the following equation:

$$
\% \text { inhibition }=\frac{I-I \ell}{I} \cdot 100
$$

\section{Adsorption Isotherm}

The adsorption of the inhibitor molecules from aqueous solutions can be regarded as a substitution adsorption process between the organic compounds in the aqueous phase and water molecules adsorbed on the electrode surface $\left(\mathrm{H}_{2} \mathrm{O}(\mathrm{s})\right)$.

$$
\operatorname{Org}(\mathrm{aq})+\mathrm{xH}_{2} \mathrm{O}(\mathrm{s})=\operatorname{org}(\mathrm{s})+\mathrm{x}\left(\mathrm{H}_{2} \mathrm{O}\right)
$$

where $\mathrm{x}$ (the size ratio) is the number of water molecules displaced by one molecule of inhibitor. The above process reaches equilibrium when the chemical potential on the left hand equal to that of the right hand side.

Adsorption isotherms are very important in determining the mechanism of electrochemical reactions. The most frequently used isotherms are those of Langmuir . Frumkin, Parsons, Temkin, Flory-Huggins, and Bockris-Swinkels [21].

These entire isotherms are of the general form:

$$
f(\theta, x) e^{(-a \theta)}=k c
$$

where $f(\Theta, x)$ is the configuration factor which depends essentially on the physical model and assumption underlying the derivation of the isotherm. The mechanism of inhibition is generally believed to be due to the formation and maintenance of a protective film on the metal surface $[22,23]$. 
Table 1. Give the values of limiting current at different mole fraction of alcohols at different temperatures.

\begin{tabular}{|c|c|c|c|c|c|}
\hline alcohols & Mole fraction $(\mathrm{x})$ & $25^{\circ} \mathrm{C}$ & $30^{\circ} \mathrm{C}$ & $35^{\circ} \mathrm{C}$ & $40^{\circ} \mathrm{C}$ \\
\hline \multirow{8}{*}{ 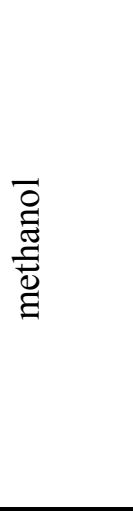 } & 0.00000 & 230 & 250 & 300 & 350 \\
\hline & 0.01135 & 210 & 220 & 240 & 270 \\
\hline & 0.02875 & 200 & 215 & 230 & 250 \\
\hline & 0.05882 & 188 & 200 & 215 & 230 \\
\hline & 0.09030 & 178 & 190 & 200 & 210 \\
\hline & 0.12329 & 170 & 180 & 190 & 200 \\
\hline & 0.15789 & 158 & 170 & 180 & 190 \\
\hline & 0.19425 & 145 & 160 & 170 & 180 \\
\hline \multirow{7}{*}{$\begin{array}{l}\overline{0} \\
\text { है } \\
\text { है }\end{array}$} & 0.00792 & 230 & 250 & 270 & 280 \\
\hline & 0.02018 & 210 & 230 & 240 & 260 \\
\hline & 0.04167 & 190 & 210 & 220 & 230 \\
\hline & 0.06459 & 180 & 200 & 210 & 230 \\
\hline & 0.08911 & 170 & 180 & 190 & 200 \\
\hline & 0.11538 & 160 & 170 & 180 & 190 \\
\hline & 0.14362 & 145 & 160 & 170 & 180 \\
\hline \multirow{6}{*}{$\begin{array}{l}\overrightarrow{0} \\
\bar{\Xi} \\
\stackrel{0}{0} \\
\text { : }\end{array}$} & 0.00302 & 210 & 230 & 250 & 280 \\
\hline & 0.00609 & 190 & 210 & 230 & 250 \\
\hline & 0.01554 & 180 & 200 & 210 & 230 \\
\hline & 0.03226 & 170 & 180 & 190 & 200 \\
\hline & 0.05028 & 160 & 170 & 180 & 190 \\
\hline & 0.06977 & 150 & 160 & 170 & 180 \\
\hline \multirow{7}{*}{ 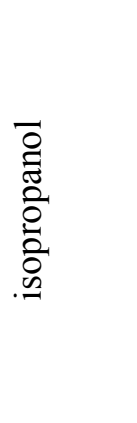 } & 0.00302 & 210 & 235 & 250 & 290 \\
\hline & 0.00609 & 180 & 205 & 220 & 240 \\
\hline & 0.01554 & 160 & 220 & 235 & 250 \\
\hline & 0.03226 & 150 & 180 & 200 & 220 \\
\hline & 0.05028 & 140 & 160 & 180 & 190 \\
\hline & 0.06977 & 135 & 150 & 160 & 170 \\
\hline & 0.09090 & 130 & 140 & 150 & 160 \\
\hline
\end{tabular}


Table 2. Give the effect of alcohols concentration on the percentage inhibition of copper electrode at different temperatures.

\begin{tabular}{|c|c|c|c|c|c|}
\hline alcohols & mole fraction $(\mathrm{x})$ & $25^{\circ} \mathrm{C}$ & $30^{\circ} \mathrm{C}$ & $35^{\circ} \mathrm{C}$ & $40^{\circ} \mathrm{C}$ \\
\hline \multirow{7}{*}{ 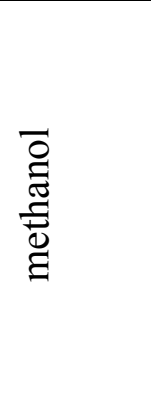 } & 0.01135 & 8.7 & 12 & 20 & 22.9 \\
\hline & 0.02875 & 13 & 14 & 23.3 & 28.6 \\
\hline & 0.05882 & 18 & 20 & 28.3 & 34.3 \\
\hline & 0.09030 & 23 & 24 & 33.3 & 40 \\
\hline & 0.12329 & 26 & 28 & 36.7 & 42.9 \\
\hline & 0.15789 & 31 & 32 & 40 & 45.7 \\
\hline & 0.19424 & 37 & 36 & 43.3 & 48.6 \\
\hline \multirow{7}{*}{ 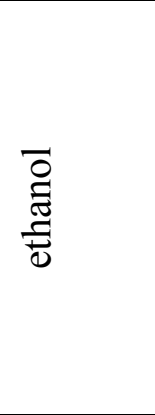 } & 0.00792 & 8 & 10.7 & 12.9 & 20 \\
\hline & 0.02018 & 16 & 17.9 & 22.6 & 25.7 \\
\hline & 0.04167 & 24 & 25 & 29 & 34.3 \\
\hline & 0.06459 & 28 & 28.6 & 32.3 & 34.3 \\
\hline & 0.08911 & 32 & 35.7 & 38.7 & 42.9 \\
\hline & 0.11538 & 36 & 39.3 & 41.9 & 45.7 \\
\hline & 0.14362 & 42 & 42.9 & 45.2 & 48.6 \\
\hline \multirow{6}{*}{ 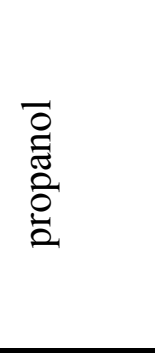 } & 0.00302 & 16 & 17.9 & 19.4 & 20 \\
\hline & 0.00609 & 24 & 25 & 25.8 & 28.6 \\
\hline & 0.01554 & 28 & 28.6 & 32.3 & 34.3 \\
\hline & 0.03226 & 32 & 35.7 & 38.7 & 42.9 \\
\hline & 0.05028 & 36 & 39.3 & 41.9 & 45.7 \\
\hline & 0.06977 & 40 & 42.9 & 45.2 & 48.6 \\
\hline \multirow{6}{*}{ 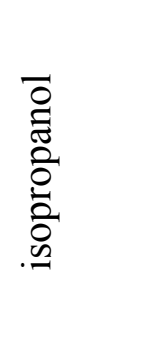 } & 0.00302 & 4 & 14.5 & 16.7 & 15.4 \\
\hline & 0.00609 & 16 & 19.4 & 22.2 & 20.5 \\
\hline & 0.01554 & 24 & 32.3 & 27.8 & 25.6 \\
\hline & 0.03226 & 32 & 38.7 & 33.3 & 30.8 \\
\hline & 0.05028 & 40 & 45.2 & 38.9 & 35.9 \\
\hline & 0.06977 & 46 & 51.6 & 44.4 & 41 \\
\hline
\end{tabular}

\section{Application of Isotherm}

The degree of surface coverage $(\Theta)$ at constant temperature was determined from the following equation[24,25].

$$
\theta=\frac{I-I \ell}{\mathrm{I}}
$$

Inhibitor adsorption characteristics can be estimated by using the Langmuir isotherm given by the following equation:

$$
K C=\frac{\theta}{1-\theta}
$$

The langmuir adsorption isotherm for copper electrode in $\mathrm{H}_{3} \mathrm{PO}_{4}$ plotted as $\Theta$ /1$\Theta$ against $\mathrm{C}$ 
at $25^{\circ} \mathrm{C}$ which give as a straight line that does not pass from the origin, i.e. Langmuir isotherm does not verify

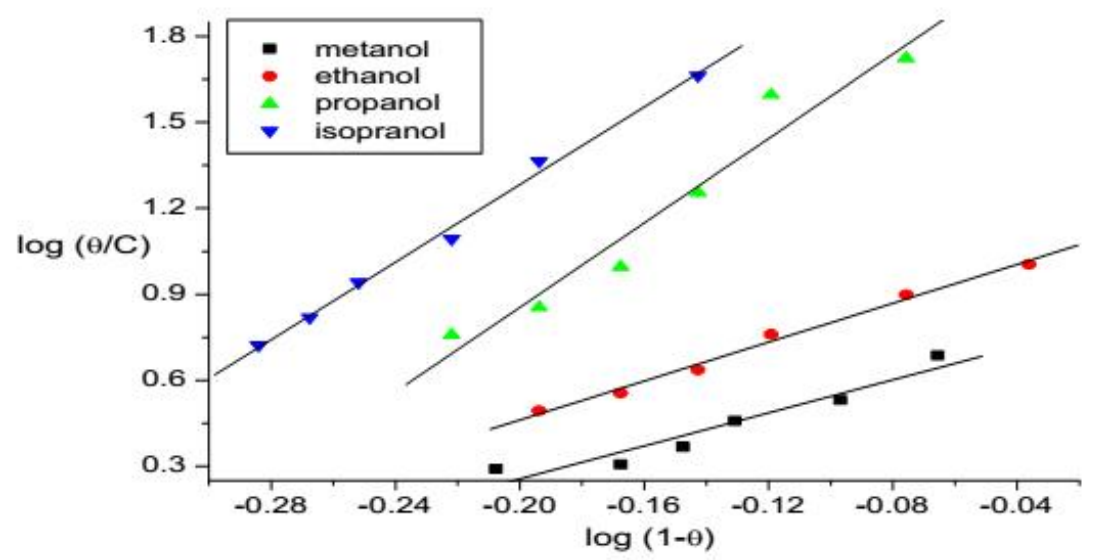

Figure 1. Flory-Huggins isotherm for methanol, ethanol, propanol and isopropanol.

Fig. 1 shows the Flory-Huggins adsorption isotherm for copper electrode in $\mathrm{H}_{3} \mathrm{PO}_{4}$ plotted as $\log \Theta / \mathrm{C}$ against $\log (1-\Theta)$ at $25^{\circ} \mathrm{C}$. A straight line is obtained with a slope $\mathrm{X}$ and intercept $\log \mathrm{x} \mathrm{K}$. The experimental data fit the Flory-Huggins adsorption isotherm, which represented by:

$$
\log (\theta / C)=\log x k+x \log (1-\theta)
$$

where $\mathrm{x}$ is the number of water molecules replaced by one molecule of the inhibitor. It is clear that, the surface coverage data are useful for discussing adsorption characteristics. The adsorption of inhibitors at the metal - solution interface may be due to the formation of electrostatic or covalent bonding between the adsorbs and the metal surface [26]. The kinetic adsorption isotherm may be written in the form [27]:

$$
\log \theta /(1-\theta)=\log k^{\prime}+y \log C
$$

From equation(6) a plot of $\log \Theta / 1-\Theta$ against $\log \mathrm{C}$ should yield a straight line with intercept of $\log \mathrm{K}^{\prime}$ and slop $=\mathrm{y}$, where $\mathrm{y}$ is the number of inhibitory molecules occupy one active site. The binding constant of adsorption $K=k^{1 / y}$, where $1 / y$ is the number of the active surface sites occupied by one molecule of the inhibitor, and $\mathrm{k}$ is the binding constant. Fig. 2 indicate a linear relationship between $\log \theta / 1-\Theta$ and $\log \mathrm{C}$ at $25^{\circ} \mathrm{C}$, and the calculated values of $1 / \mathrm{y}$ and $\mathrm{K}$ are given in Table 2. And from this table, it is obvious that the value of $1 / \mathrm{y}$ for all compounds are higher than one indicating that, the given inhibitors molecules are attached to more than one active site. The free energy of adsorption ( $\Delta$ Gads). At a different concentration of the alcohols as calculated from the following equation:

$$
\Delta \mathrm{G}_{\mathrm{ads}}=-\mathrm{RT} \operatorname{In}(55.5 \mathrm{~K})
$$

the value 55.5 is the concentration of water in the solution $\mathrm{mol} / 1$.

The values of $\Delta \mathrm{G}_{\mathrm{ads}}$ are given in Table (3). In all cases, the $\left(\Delta \mathrm{G}_{\mathrm{ads}}\right)$ values are negative and lie in the range of $10.2-16.1 \mathrm{KJ} / \mathrm{mol}$. The most efficient inhibitor shows the most negative $\left(\Delta \mathrm{G}_{\mathrm{ads}}\right)$ value. This suggests that, they are strongly 
adsorbed on metal surfaces. The negative values of ( $\Delta \mathrm{Gads})$ indicate that the spontaneous ion of the inhibitors. It's found that ( $\Delta$ Gads) values are more positive than (-40) indicating that the inhibitors are physically adsorbed on the metal surface. Similar results have also been reported by Talati [27].

Table 3. Gives the values of $K, X, 1 / Y$ and $-\Delta G$ ads (calculated free energy of adsorption in $\mathrm{kJ} \cdot \mathrm{mol}^{-1}$ ) of $\mathrm{H}_{3} \mathrm{PO}_{4}$ of some organic alcohols to Flory - Huggins, and Kinetic Adsorption Isotherm constants at $25^{\circ} \mathrm{C}$.

\begin{tabular}{cccccccc}
\hline & \multicolumn{3}{c}{ Flory - Huggins } & \multicolumn{5}{c}{ Kinetic Adsorption Isotherm } \\
\hline & $\mathrm{X}$ & $\mathrm{K}$ & $-\Delta \mathrm{G}_{\text {ads }}$ & $\mathrm{K}^{\prime}$ & $1 / \mathrm{Y}$ & $\mathrm{K}$ & $-\Delta \mathbf{G}_{\text {ads }}$ \\
\hline Methanol & 3.563 & 2.13 & 11.5 & 1.387 & 1.62 & 1.7 & 11.02 \\
Ethanol & 2.95 & 4.23 & 13.2 & 2.663 & 1.44 & 4.093 & 13.15 \\
Propanol & 7.363 & 28.82 & 17.9 & 10.277 & 2.797 & 1.206 & 10.19 \\
Iso Propanol & 1.723 & 12.37 & 15.8 & 9.142 & 1.173 & 13.41 & 16.1 \\
\hline
\end{tabular}

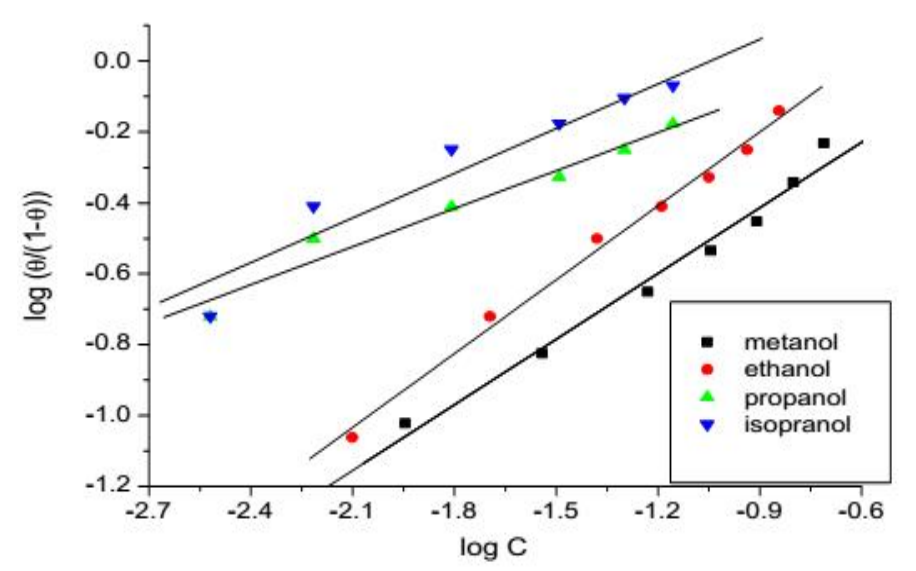

Figure 2. Kinetic adsorption isotherm for methanol, ethanol, propanol and isopropanol

\section{Effect of temperature and thermodynamic treatment of the reaction}

The effect of temperature on the $\mathrm{Cu}$ electro polishing rate in absence and presence of organic additives was determined in the temperature ranges between $\left(25-40^{\circ} \mathrm{C}\right)$. It was observe that the electro polishing rate increases with temperature for different concentrations of organic additives. Values of $E_{a}$ that have been derived from the slopes of Arrhenius [28].

It is obviously seen that the Ea values in the absence and presence of organic additives are less than $<40 \mathrm{~kJ} \mathrm{~mol}^{-1}$, also indicating that the diffusion processes are controlling the electropolishing reaction [29]. In this research, the thermodynamic parameters such as change in free energy $\Delta \mathrm{G}^{*}$, enthalpy $\Delta \mathrm{H}^{*}$ and entropy $\Delta S^{*}$ were calculated in the same way as the related researches did in literature [30-33]. From transition state equation [37] a straight line was obtained, 
from which can $\Delta \mathrm{H}^{*}$ and $\Delta \mathrm{S}^{*}$ be calculated from the slope and intercept, respectively. The free energy change, $\Delta \mathrm{G}^{*}$, can be represented as follows:

$$
\Delta \mathrm{G}^{*}=\Delta \mathrm{H}^{*}-\mathrm{T} \Delta \mathrm{S}^{*}
$$

The result indicated by that the tested compounds acted as inhibitors through adsorption on copper surface, which resulted in the formation of a barrier to mass and charge transfer. The values of $\Delta \mathrm{H}^{*}$ reflect the strong adsorption of these compounds on copper surface. The negative values of $\Delta S^{*}$ pointed to a greater order produced during the process of activation.

Table 4. The values of $\mathrm{E}^{*}$ and all thermodynamic parameters for all different concentration of the organic alcohols.

\begin{tabular}{|c|c|c|c|c|c|c|}
\hline inhibitor & $\begin{array}{l}\text { Mole } \\
\text { fraction } \\
(\mathrm{X})\end{array}$ & $\begin{array}{c}\Delta \mathrm{G}^{*} \\
\left(\mathrm{kJmol}^{-1}\right)\end{array}$ & $\begin{array}{c}-\Delta \mathrm{S}^{*} \\
\left(\mathrm{Jmol}^{-1} \mathrm{~K}^{-1}\right)\end{array}$ & $\begin{array}{c}\Delta \mathrm{H}^{*} \\
\left(\mathrm{kJmol}^{-1}\right)\end{array}$ & $\begin{array}{c}\mathrm{Ea}^{*} \\
\left(\mathrm{kJmol}^{-1}\right)\end{array}$ & $\begin{array}{c}\text { Dielectric } \\
\text { constant }\end{array}$ \\
\hline \multirow{7}{*}{ 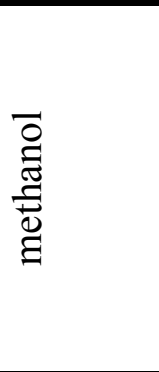 } & 0.01135 & 59.6 & 133 & 19.8 & 22.3 & 80.37 \\
\hline & 0.02875 & 59.8 & 165 & 10.5 & 13.02 & 71.02 \\
\hline & 0.05882 & 59.8 & 170 & 8.9 & 11.4 & 61.24 \\
\hline & 0.09030 & 60 & 174 & 8.03 & 10.5 & 51.53 \\
\hline & 0.12329 & 60.1 & 181 & 6 & 8.5 & 41.46 \\
\hline & 0.15789 & 60.2 & 182 & 5.9 & 8.4 & 32.20 \\
\hline & 0.19424 & 60.4 & 179 & 7 & 9.4 & \\
\hline \multirow{6}{*}{ 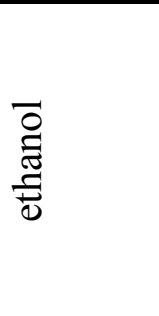 } & 0.00792 & 59.5 & 173 & 7.9 & 10.3 & 80.37 \\
\hline & 0.02018 & 59.4 & 173 & 8.1 & 10.6 & 68.66 \\
\hline & 0.04167 & 59.9 & 177 & 7.1 & 9.6 & 56.49 \\
\hline & 0.06459 & 60.1 & 169 & 9.7 & 12.1 & 44.67 \\
\hline & 0.08911 & 60.2 & 182 & 5.9 & 8.4 & 33.89 \\
\hline & 0.11538 & 60.4 & 181 & 6.4 & 8.8 & 25.00 \\
\hline \multirow{6}{*}{$\begin{array}{l}\overline{0} \\
\text { त्ञ } \\
\text { Oे } \\
0\end{array}$} & 0.14362 & 59.7 & 159.5 & 12.2 & 14.6 & \\
\hline & 0.00302 & 60 & 161.9 & 11.7 & 14.2 & 80.37 \\
\hline & 0.00609 & 60.1 & 169.1 & 9.7 & 12.1 & 66.54 \\
\hline & 0.01554 & 60.2 & 182.3 & 5.9 & 8.4 & 51.68 \\
\hline & 0.03226 & 60.4 & 181.1 & 6.4 & 8.8 & 37.51 \\
\hline & 0.05028 & 60.5 & 179.8 & 6.9 & 9.4 & 26.83 \\
\hline \multirow{6}{*}{ 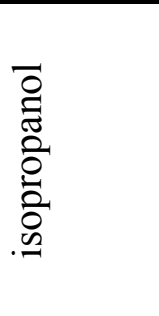 } & 0.06977 & 59.7 & 155.2 & 13.5 & 15.9 & 20.81 \\
\hline & 0.00302 & 60.1 & 161.2 & 12.04 & 14.5 & 80.37 \\
\hline & 0.00609 & 60.2 & 136.8 & 19.4 & 21.9 & 65.72 \\
\hline & 0.01554 & 60.5 & 145.9 & 17 & 19.5 & 51.07 \\
\hline & 0.03226 & 60.7 & 158 & 13.6 & 16.09 & 36.28 \\
\hline & 0.05028 & 60.8 & 172.8 & 9.2 & 11.7 & 24.44 \\
\hline
\end{tabular}

This can be achieved by the formation of an activated complex representing the association or fixation with consequent loss in the degree of freedom of the system during the process. $\Delta \mathrm{G}^{*}$ values showed a limited increase with a rise in the concentration of organic additives revealing that weak dependence of $\Delta \mathrm{G}^{*}$ on 
the composition of the organic additives can be attributed largely to the general linear composition between $\Delta \mathrm{H}^{*}$ and $\Delta \mathrm{S}^{*}$ for the given temperature $[28,34]$.

Thermodynamic function of electropolishing of copper in alcohols gives evidence of structural change occurring in the solution as the type of solvents is changed. The effect can arise from the solvent properties and from the salvation properties of ions in different solvents [35]. Table 4 shows the variations of $\Delta G^{*}$, $\Delta \mathrm{H}^{*}$ and $\Delta \mathrm{S}^{*}$ with the mole fraction of alcohols. The gradual increases of both $\Delta \mathrm{H}^{*}$ and $\Delta \mathrm{S}^{*}$ give a good indication of preferential salvation of metal surface in the presence of aprotic solvents which is a criterion of specific salvation. The weak dependence of $\Delta \mathrm{G}^{*}$, on the composition of the organic solvents can be attributed largely to the general linear compensation between $\Delta \mathrm{H}^{*}$ and $\Delta \mathrm{S}^{*}$ for the given temperature. Table 4 shows that, the free energy change increases positively with increasing dielectric constant of the solvent. This show that as the dielectric constant decreases more work as required to keep the ions apart and therefore the dissolution of $\mathrm{Cu}$ is decreased, as the dielectric constant decrease. There is less spontaneity and less dissolution of the lower dielectric constant. Table 4 show that for any solvent, as the temperature increases the dielectric constant decreases and the force among the ion greater [36]. This is attributed the fact that as temperature increases, the viscosity of solvent decreases, so salvation decrease and mobility of $\mathrm{Cu}^{++}$increases, this led to increases in the rate of mass transfer.

\section{The isokinetic relationship}

Variation in the rate within series may be caused by changes in either, or both, the enthalpy or the entropy of activation the correlation of $\Delta \mathrm{H}^{*}$ with $\Delta \mathrm{S}^{*}$ is linear relationship may be stated algebraically :

$$
\begin{aligned}
& \Delta \mathrm{H}^{*}=\beta \Delta \mathrm{S}^{*}+\text { constant } \\
& \delta \Delta \mathrm{H}^{*}=\beta \Delta \mathrm{S}^{*}
\end{aligned}
$$

The operator, $\delta$, concerns the difference between any two reactions in the series. Substituting from the equation (11) into the familiar relationship:

$$
\delta \Delta \mathrm{H}^{*}=\delta \Delta \mathrm{G}^{*}+\mathrm{T} \delta \Delta \mathrm{S}^{*}
$$

we obtain

$$
\beta \delta \Delta S^{*}=\delta \Delta G^{*}+T \delta \Delta S^{*}
$$

Where $\delta \Delta \mathrm{G}^{*}=$ zero, $\beta=\mathrm{T}$. In other words, the slop in a linear plot of $\Delta \mathrm{H}^{*}$ versus $\Delta S^{*}$ is the temperature at which all reactions that conform to the line occur at the same rate. $\beta$ there for known as the isokienetic temperature. The isokientic plot of $\Delta \mathrm{H}^{*}$ and $\Delta \mathrm{S}^{*}$ for different concentration of the organic alcohols, Fig. 3 and Table 4 was found to be linear and the isokienetic temperature $(\beta)$ was computed from the slop of the plot as $283 \mathrm{~K}, 263 \mathrm{~K}, 266 \mathrm{~K}$, and $280 \mathrm{~K}$. These values are much lower than that of the experimental temperature $298 \mathrm{~K}$ indicating that the rate of the reaction is Entropy controlled. 


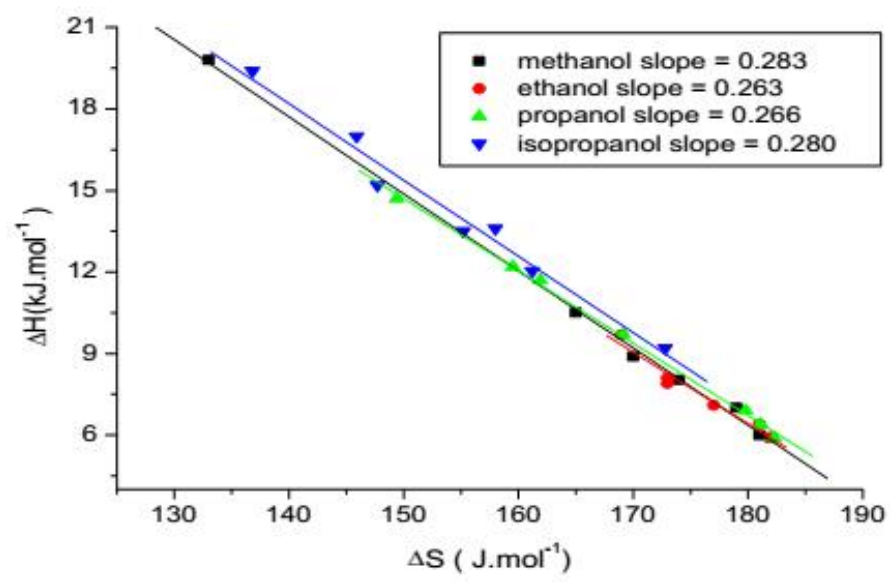

Figure 3. The isokinetic relationship for methanol, ethanol, propanol and isopropanol.

\section{Effect of dielectric constant}

The variation of $\log$ I $\ell$ with the reciprocal of the dielectric constant of the medium. D-1, over the whole range of solvent composition shows non-linear for all the aqueous solvent systems, Fig. (4). The absence of linearity suggests a large differential effect of solvent structure acting on the initial and transition states. This was shown from the extension of the equation of Laidler and Landskroaner [37], which allows changes in solvent structure with varying solvent composition [38].

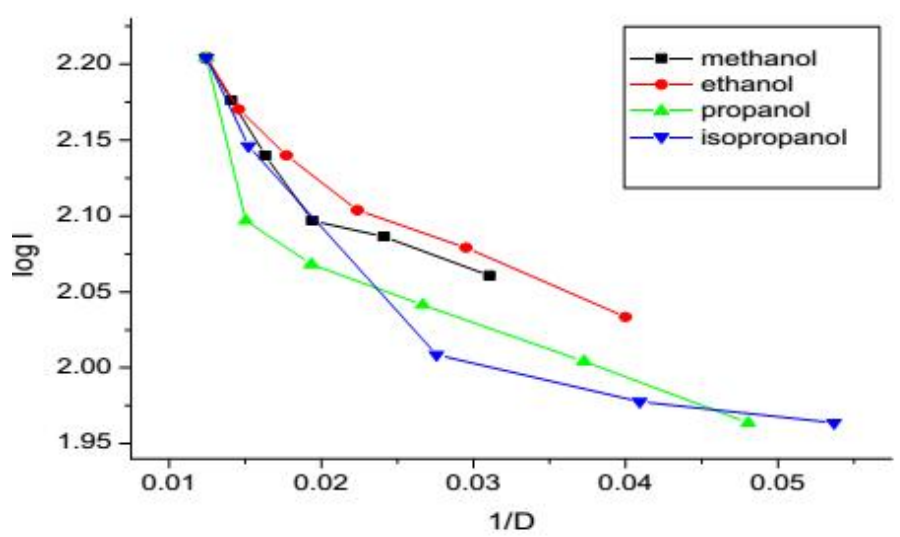

Figure 4. The variation of $\log$ I $\ell$ with the reciprocal of the dielectric constant of the medium. $\mathrm{D}^{-1}$, over the whole range of solvent composition

\section{Solvent effect on limiting current}

Protic solvent: The variation of the physicochemical properties of the medium such as viscosity, density and dielectric constant, as a result of adding organic solvents, were expected to affect the rate of mass transfer process by affecting the diffusivity and the activity of the metal ions. The rate of corrosion of copper was studied in methanol, ethanol, propanol and isopropanol- $\mathrm{H}_{2} \mathrm{O}$ mixtures of different compositions at 298-313 K. The addition of organic solvent may change the reactive species existing in solution by changing the composition of the salvation shell. Copper ions are solvated with water molecules to form $[\mathrm{Cu}$ 
$\left.\left(\mathrm{H}_{2} \mathrm{O}\right)_{4}\right]^{2+}$ in aqueous solution, alcohol molecules may replace some of the ligated water molecules and this would affect the mobility of copper ion [39], but in many cases this cannot be separated from the effect of the viscosity of the solvent. Another explanation for the decrease in the rate of corrosion would be that the addition of alcohol has a marked effect on increasing the basicity of the medium. The relative affinities of $\mathrm{H}_{2} \mathrm{O}$ or the non aqueous component toward $\mathrm{Cu}^{2+}$ may be expected to arise from the relative salvation capacities of solvent dipoles exerted largely through hydrogen bond formation. The strength of hydrogen bonding should be largely guided by the relative charge densities on the oxygen and hydrogen charge centers of the isolated dipoles. To a first approximation, the isolated dipoles of $\mathrm{H}_{2} \mathrm{O}$ and $\mathrm{ROH}$, indicated by Feakins [40] can be represented as follows:
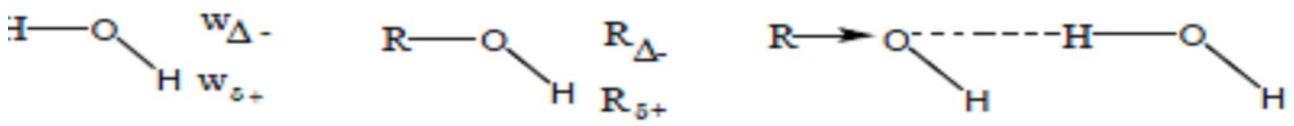

Owing to the inductive effect of the R-group in alcohols, the negative charge density on the oxygen

Atom $\left(\mathrm{R} \Delta^{-}\right)$is presumably somewhat greater than the corresponding quantity in water $\left(\mathrm{w} \Delta^{-}\right)$. As a result, the protonic character of the $\mathrm{H}$ atom of $-\mathrm{OH}$ group in alcohols $(\mathrm{R} \delta+)$ is weaker than that in water $(\mathrm{w} \delta+)$, i.e., $\mathrm{R} \Delta->\mathrm{w} \Delta-$ and $\mathrm{R} \delta+<\mathrm{w} \delta+$. Furthermore, alcohol molecule is also expected to induce, in water molecule hydrogen bonded to it, a positive charge on the hydrogen atom. These effects are likely to be relayed over several molecular diameters, rendering all molecules in methanol, ethanol, propanol or isopropanol $-\mathrm{H}_{2} \mathrm{O}$ mixtures more basic and less acidic than in pure water. The viscosity is high because the relatively large number of hydrogen bonds would require more energy to be ruptured in the formation of the activated state. The inhibitory action of alcohols depends on stress effect taking part in the absorption of the inhibitor molecule and their electron charge density, molecular size of such alcohols. The order of inhibition efficiency for the alcohols is

isopropanol $>n$-propanol $>$ ethanol $>$ methanol.

\section{Conlcusions}

Electropolishing of copper in phosphoric acid is considered as corrosion rate of copper. It is measured by measuring the limiting current .

The rate of corrosion decreases by adding of organic alcohols ( methanol, ethanol, propanol, and isopropanol).

The rate of inhibition ranged from $8.7-53.8 \%$, depending on the type of the alcohols and its concentration.

The corrosion rate increases by increases the temperature and the activation energy of the reaction is less than $40 \mathrm{~kJ}$; i.e., the reaction is diffusion controlled. All alcohols verify Langmuir, Flory-Huggins and Kinetic Adsorption Isotherm. 


\section{References}

1. Caroline MM, Christian P, Hannes CS, et al. Langmuir. 2008;24:1426914275.

2. El-Maksoud SAA. Int J Electrochem Sci. 2008;3:528-555

3. Schumacher R, Muller A, Stockel W. J Electroanal Chem. 1987;219:311317.

4. Moretti G, Molokanov VV, Quartarone G, et al. Corrosion. 1998;54:135144.

5. Khaled KF, Hackerman NI. Electrochim Acta. 2004;49:485-495.

6. Ahmed AM, Ghozy SM. Int J Electrochem Sci. 2012;7:7720-7739

7. Christy AG, Lowe A, Otieno-Alego V, et al. J Appl Electrochem. 2004;34:225-233.

8. Wang C, Chen S, Zhao S. J Electrochem Soc. 2004;151:11-15.

9. Ma HY, Yang C, Yin BS, et al. Appl Surf Sci. 2003;218:143-153.

10. Otmacic H, Stupnisek-Lisac E. Electrochim Acta. 2002;48:985-991.

11. Scendo M, Poddebniak D, Malyszko J. J Appl Electrochem. 2003;33:287293.

12. Otmacic H, Telegdi L, Papp K, et al. J Appl Electrochem. 2004;34:545-550.

13. Dalali A, Hammouti B, Touzani R, et al. Anti-Corros Methods Mater. 2002;49:96-102.

14. Fontana MG, Staehle KW. Advances in corrosion science and technology. New Yourk: Plenum Press; 1970.

15. Jacquet PA. Trans. Electrochem Soc. 1936;69:629-655.

16. Hackerman N, Hurd RM. First International Congress of Metallic Corrosion. London: Butter Worth; 1962. P. 166.

17. Walton HF. J Electrochem Soc. 1950;97:219-226.

18. Wilke CR, Eiesenberg M, Tobias CW. Chem Eng Prog. 1953;49:663-674.

19. Seleim SM, Ahmed AM, El-Adl AF. Int J Electrochem Sci. 2014;9:20162028

20. Mansfeld F, Kenkel JV. Corros Sci. 1975;15:183-198.

21. Frumkin AN. Z Phys Chem. 1925;116:466-484

22. Ateya U, El-Anadouli B, El-Nizamy F. Corros Sci. 1984;24:509-515.

23. Chandrasekaran, Kannan K. Bull Electrochem. 2004;20:471-479.

24. Oguize EE, Okolue BN, Ogukwe CL, et al. Bull Electrochem. 2004;20:421427.

25. Ebenso EE, Ekpe UJ, Ita BI, et al. Mater Chem Phys. 1999;60:79.

26. Ebenso EE. Bull Electrochem. 2003;19:209-216.

27. Talati D, Darji M. J Ind Chem Soc. 1988;65:94-99.

28. Noor EA. Mater Chem Phys. 2009;114:533-541.

29. Sorkhabi HA, Shaabani B, Seifzdeh D. Electrochim Acta. 2005;50:34463458.

30. Solmaz R, Kardas G, Yazici B, et al. Colloids Surf A: Physicochem Eng Aspects. 2008;312:7-17.

31. Malkoc E, Nuhoglu Y. J Hazard Mater. 2005;127:120-128.

32. Malkoc E, Nuhoglu Y, Dundar M. J Hazard Mater. 2006;138:142-151.

33. Nuhoglu Y, Malkoc E. Bioresour Technol. 2009;100:2375-2380. 
34. Quinet M, Lallemand F, Ricq L, et al. Electrochim Acta. 2009;54:15291539.

35. McIntyre M, Amis ES. J Chem Eng Data. 1968;13:371-375.

36. Ahmed AM. Bull Electrochem. 1991;7:167-172.

37. Laidler KJ. Chemical Kinetics. 2nd ed. New York: McGraw-Hill; 1965.

38. Ismail AM, Harfoush AA, Abdel-Rahman HH. Afinidad. 2002;479:81-87.

39. Tanaka N. Electrochim Acta. 1976;21:701-719.

40. Feakins D. Physico-chemical processes in mixed aqueous solvents. In: Franks F, editor. London: Heinemann; 1976. p. 17. 